2005. - Режим доступу до ресурсу: http://www.irbnet.de/daten/iconda/ CIB4274.pdf.

19. Sonja C. Economic incentives for sustainable construction - the contribution of energy performance-, solar- and photovoltaic contracting / Cypra Sonja. // SB05 Tokyo: Action for Sustainability - The 2005 World Sustainable Building Conference in Tokyo. - 2005. - C. 4101-4108.

20. Gorse Ch. Refurbishment and Upgrading of Buildings / Christopher Gorse, David Highfield/ - 2 edition. New Jork, Spon Press, 2009. - 272 p.

21. Yudelson J. Green Building Trends: Europe / Jerry Yudelson. Island Press, 2009. - $160 \mathrm{p}$.

22. Friedman D. Historical Building Construction: Design, Materials, and Technology (Second Edition) / Donald Friedman. - W. W. Norton \& Company. New Jork - London, 2010. - 320 p.

23. Burton S. Handbook of Sustainable Refurbishment: Housing / Simon Burton. - Routledge, 2011. - 192 p.

DOI https://doi.org/10.30525/978-9934-588-79-2-2.29

\title{
INFLUENCE OF ENVIRONMENTAL ASPECTS OF DESIGN ON THE AESTHETICS OF ARCHITECTURAL SPACE
}

\author{
Pylypchuk O. D. \\ $P h D$,
}

Associate Professor at the Department of Drawing and Painting

Kyiv National University of Construction and Architecture

\section{Krivenko O. V.}

$P h D$,

Associate Professor at the Department of Architectural Constructions

Kyiv National University of Construction and Architecture

\section{Polubok A. P.}

Associate Professor at the Department of Drawing and Painting

Kyiv National University of Construction and Architecture

$$
\text { Kyiv, Ukraine }
$$

Formulation of the problem. Modern construction and urban environment highlight the urgent need for aesthetic perception and the creation of a visual ecology of space (interior and open public space). In such conditions, taking care of the psychological state of people takes a central place 
in certain areas of science and art, the problems of visual ecology in various spheres of human life, including healthcare, become relevant for achieving a safe, fruitful and fruitful productive life.

Today, as one of the ways to regulate and implement this problem through design, is the globally defined standards of the international concept WELL [1].

Results and discussion. Technological progress has radically changed the style and living conditions of a modern person who spends his time mainly in the premises of buildings (work, leisure, education, living, etc.). An artificial human habitat is being formed. Thus, an important task of modern architecture and design is to ensure healthy and comfortable conditions for humans in a predominantly artificial environment of buildings. This requires both biological and psychological requirements to be considered. The use of open spaces makes it possible to establish visual and social contact of people in a building, and the integration of elements of artistic means that improve the aesthetics of an architectural space provides psychological comfort for a person.

The COVID-19 pandemic highlighted the urgent need to improve the environmental friendliness of the environment. Quarantine and restrictive measures to avoid infection of people have led to their even greater isolation from the external environment. Providing isolation requirements for physiological safety, despite reducing the risk of human infection, negatively affect the psychological state of people. For its settlement, means of increasing the aesthetics of the architectural space can be used, harmonizing the internal state of a person.

The visual environment surrounding a person is organized by separate spatial types of art - architecture, design, monumental decorative, decorative and applied arts. The object of a work of art has a utilitarian and instrumental role, carries a certain emotional mood - as a means of creating balance and harmony in architecture, and the composition of form, colour and light is an emotional synthesis between emotional impression and semantic meaning in this case, the aesthetic impact from the perception of the environment, taking into account the beautiful, is formed with the help of a person's assessment of reality.

In the interior, fine art can be a source of beauty, admiration, inspiration, excitement, which can obey the «laws of beauty» in design, and accordingly it is one of the main means of aesthetic impact. The feeling of comfort and cosiness obtained from the perception of art, at the same time solves the problem of a stimulating effect, improves mood, and creates spiritual harmony. 
The internationally recognized standards for the international rating certification of buildings «Building Standard WELL» indicate that the integration of works of art into the interior increases the rating of a building, and is one of the conditions for a comfortable and full-fledged existence of a person in it. Integration of works of fine art into the interior helps not only to diversify the composition of the design solution, but also to positively affect the emotional and psychological state of a person, to create harmony of space and visual comfort of the environment.

1. «Movement» standard - promotes physical activity in everyday life through ecological design, where the introduction of visual arts is the stimulation of physical activity as a prerequisite for increasing the culture of health promotion.

2. In the «Mind» standard, where «Integrate Beauty and Design» designing a room with elements of a beautiful design (using art in the interior) is a prerequisite for a balanced mental state of a person.

It should also be borne in mind that outdoor walks are always better to restore the physical and psycho-emotional state of a person. Here, the task of creating favourable aesthetic conditions for visual perception in the urban space becomes urgent, compensating for the disadvantages of an urbanized dense environment. The introduction of elements of fine art into the urban space is accompanied only by positive emotions in people. A synthesis of art and architecture, which are aesthetically consistent and comfortable for perception in an open public space, provide the requirements of visual ecology [2].

Conclusions. Aesthetic and comfortable visual environment for a person is a physiological necessity that can be achieved by introducing elements of artistic means that can compensate for the shortcomings of the surrounding space, creating an ecology of perception. At the same time, the visual ecological environment created by architects, designers and artists with the help of all types of art directly affects a person who, in the process of perception, receives aesthetic pleasure and psychological comfort. This is confirmed by the implementation of the relevant provisions in the world standards for ensuring a healthy environment for humans «Building Standard WELL».

\section{References:}

1. WELL. https://v2.wellcertified.com/health-safety/en/overview (date of the application 17.09.20).

2. Gibson, J.J. (1979). The Ecological Approach to Visual Perception. Boston: Houghton Mifflin. 